\title{
TEORIAS COSMOLÓGICAS NO ESTOICISMO ANTIGO ${ }^{1}$
}

\author{
Gabriela Baião \\ PPGFil- Universidade de Lisboa
}

\begin{abstract}
This paper describes some of the main explanatory points concerning the system of the Universe, just as it has been understood by the ancient Stoics. If, in a first analysis, it can be included in preceding systems of the Greek philosophers (concerning its genesis, structure, way of perpetuation), there are other divergent aspects that deserve our attention. Following a tradition largely disseminated in the Ancient East, from India to the Arabs and to Mesopotamia, stands out their theory of the universal burning and the conception of cosmic cycles, according to which the Universe is submitted to an eternal movement of deaths and renewals. We must equally point out, against the models of Plato and Aristotle, their defence of the extra-cosmic void that served as a basis to the development of physical theories whose nature is strictly stoic.
\end{abstract} Keywords: Greek cosmology, stoicism, Hellenistic Philosophy.

Resumo: O presente estudo descreve algumas das principais teses explicativas do sistema do Universo, tal como foi entendido pelos primeiros Estóicos. Se, num primeiro momento, a sua visão se integra em modelos gregos precedentes (no que respeita à sua génese, estrutura, modo de conservação), outros aspectos divergentes há que merecem a nossa atenção. Incorporando uma tradição muito disseminada no Antigo Oriente, da Índia ao mundo árabe e à Mesopotâmia, sobressai a sua teoria da conflagração universal e 0 conceito de periodicidade cósmica, segundo o qual o Universo se encontra submetido a um eterno movimento de mortes e restaurações. Igualmente de salientar, contra o modelo platónico-aristotélico, é a sua defesa do vazio extra-cósmico que serviu de base ao desenvolvimento de teorias físicas de carácter estritamente estóico.

Palavras-chave: Cosmologia grega, estoicismo; Filosofia Helenística.

1 Conferência proferida em Segundos Encontros de Filosofia Antiga: Cosmogonias: Mito, Filosofia, Ciência, Organização da Associação de Professores de Filosofia, 3 de Outubro de 2009. Designa-se por estoicismo antigo o primeiro período da escola, entre finais do séc. IV e séc. III a. C., correspondente ao período de formação e sistematização da doutrina. Centrado em Atenas, tem por representantes Zenão de Cítio, o fundador, Cleantes de Asso e Crísipo de Soles. 
A concepção do Universo pelos Estóicos é marcada pelo geocentrismo, predominante em toda a antiguidade. Do globo terrestre ao firmamento existe um único mundo, fechado sobre si mesmo, em actividade contínua. A forma esférica do mundo é a que melhor serve para explicar o seu movimento e o seu modo de conservação. As suas diferentes partes, a terra, a água, o ar, o fogo, encontram-se sucessivamente dispostas, reguladas por leis próprias e sustentando-se mutuamente. No ponto de contacto entre o ar e o fogo está a esfera da Lua. Sucedem-se depois as esferas compostas de um éter progressivamente mais subtil, as esferas de Mercúrio, de Vénus, do Sol, de Marte, de Júpiter, de Saturno, terminando finalmente na esfera das estrelas fixas. No exterior do mundo estende-se um vazio infinito, imaterial e eterno.

O Universo é pensado como constituído a partir de dois princípios, inengendrados e imperecíveis: a matéria, substância única e indiferenciada, e a causa ou o logos unificador que lhe confere organização. Quatro elementos entram na composição do mundo: o fogo e o ar, sob as formas do quente e do frio, são os elementos activos que o penetram, a água e a terra, sob as formas do húmido e do seco, constituem os seus elementos passivos. Tomados em conjunto eles formam a substância sem qualidade, a matéria.

Os Estóicos possuem uma explicação para a origem do Universo. $\mathrm{O}$ nascimento do mundo tem lugar quando, a partir do fogo, a substância, que no início existe em si mesma, se transforma em água por intermédio do ar. $\mathrm{O}$ $\log o s$ do mundo, a sua «razão espermática», permanece no líquido à semelhança de um sémen que em si contém o embrião. Fecundada a matéria, esta é restituída, apta para receber a sua acção para a geração dos outros seres: enquanto a terra toma a sua existência da água, o ar exala-se em vapores; ao tornar-se mais ténue transforma-se em fogo que se espalha em círculo ao redor do mundo. Desenvolvem-se seguidamente, conforme a mistura dos elementos, os planetas e o Sol, as plantas, os animais e os outros géneros de seres. ${ }^{2}$

O Universo é um ser animado, dotado de vida, de inteligência e de movimento próprio. É possível apoiar esta concepção nos argumentos platónicos sobre a natureza da alma e o princípio do movimento. Tudo quanto se move a si mesmo não é outra coisa senão alma, apenas o ser que

${ }^{2}$ Cf. H. von ARNIM, Stoicorum Veterum Fragmenta, II, pp. 179-180 [§ 8. Quomodo ortus sit mundus]. 
retira de si o seu princípio do movimento é um ser animado. Tal é também a condição do Universo: o seu movimento, crescimento e conservação são impulsionados pela alma do mundo, o fogo eterno que espontaneamente se move a si mesmo. ${ }^{3}$

A dependência das esferas entre si e o modo de conservação de todo o sistema encontram também aqui a sua explicação. Entre os elementos realizam-se trocas cíclicas, a terra, o mar e os cursos de água oferecendo o alimento ao céu e aos astros, por meio das suas exalações, recebendo destes, em troca, algum benefício. Neste processo nada perece, a não ser o pouco que é consumido pelos astros e pela chama do fogo.

O Universo porém não é eterno, a sua existência está ligada a ciclos cósmicos no decurso dos quais o mundo se forma e se dissolve. No termo de um ciclo, ele reúne-se novamente e todos os seres, reconduzidos aos elementos, retornam ao fogo primitivo. A conflagração

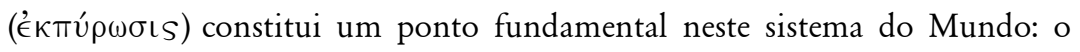
mundo inteiro incendiar-se-á quando, esgotados os vapores, não puder mais ser alimentado pela terra e quando, esgotada a água, o ar não puder mais voltar a constituir-se. Desta forma, apenas o fogo restará, mas, por seu meio, operar-se-á infinitamente a renovação do mundo. O Universo viverá outros ciclos absolutamente idênticos, porque este fogo é eterno e invariável na sua essência. ${ }^{4}$

A anterior representação do Universo enquadra-se nos modelos da física antiga, assimilando elementos dos pré-socráticos à cosmofísica aristotélica. No que concerne à cosmogonia são igualmente de referir as afinidades do pensamento estóico com o pensamento de Heraclito: a identificação do fogo com a causa primordial, o logos do Universo; a geração de todas as coisas a partir do fogo por um processo de condensação e

\footnotetext{
${ }^{3}$ V. CícERo, de Natura Deorum, II, 12, 32; PLATÃo, Phaedrus, 245c; Leges, X, 892 a ss.

${ }^{4} \mathrm{Cf}$. CícERO, Ibidem, II, 46, 118. O dogma da conflagração não será aceite por todos os estóicos no decurso dos séculos de evolução da escola. Um dos principais representantes do estoicismo médio, Panécio de Rodes, diverge neste ponto, ao defender a eternidade do cosmo.
} 
rarefacção ${ }^{5}$; a dissolução periódica do mundo pelo fogo, conhecida no

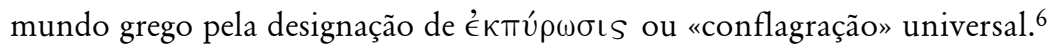

No que respeita à estrutura do Universo várias são as alusões aos modelos comummente aceites: o esquema do Universo das duas esferas, que deu lugar à forma mais elaborada das esferas concêntricas, ambos fundados na observação do movimento dos corpos celestes (modelo platónicoaristotélico). Quanto à forma da distribuição dos elementos no cosmo, a

\footnotetext{
${ }^{5}$ Citamos parte do fr. 31 de Heraclito: "Turbilhões de fogo: primeiro mar, e do mar metade terra, metade

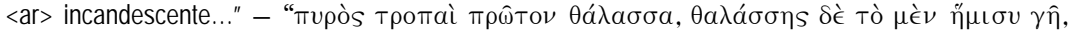

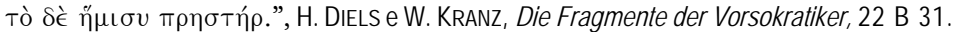

${ }^{6} \mathrm{O}$ interesse dos primeiros estóicos por Heraclito é objecto de alguma controvérsia por parte dos especialistas da filosofia antiga. Sem querer tomar um ou outro partido, convém referir que os testemunhos antigos dão prova da sua veracidade (Cleantes de Asso terá escrito uma obra em quatro livros intitulada Exegeses de Heraclito, que se perdeu). Estudos recentes têm, do mesmo modo, questionado a relação entre as duas cosmologias. É o caso de A. A. Long em "Heraclitus and Stoicism", do qual cito um excerto: "Este estudo tem por objectivo repensar e exemplificar a influência de Heraclito sobre os estóicos, especialmente sobre Cleantes. É um vasto assunto e não pretendo tratá-lo exaustivamente aqui. Espero, contudo, provar que a tendência actual para reduzir a influência de Heraclito no estoicismo primitivo não está bem fundamentada. É preciso realçar que não tenciono, com a minha tese, lançar a dúvida sobre a atenção dada pelos estóicos a posições tomadas por outros filósofos seus contemporâneos. Não irei sugerir que Heraclito foi o seu ponto de partida na cosmologia. Mas a sua importância, sobretudo em Cleantes, como defenderei, foi fundamental. Ao tentar demonstrá-lo, somos confrontados com uma série de questões, todas elas interessantes e dignas de serem colocadas. Que conhecimento de Heraclito tinham os antigos estóicos? Tinham eles o seu próprio método de interpretação ou provinha ele da obra de outros, sobretudo de Aristóteles e Teofrasto? Terão os estóicos meramente deturpado os pontos de vista de Heraclito para os ajustarem às suas necessidades preconcebidas ou tem a sua interpretação, em certos casos, um fundamento válido no pensamento de Heraclito? Acima de tudo, por que motivo se interessaram eles por este pensador remoto e extraordinariamente difícil?" - "The purpose of this paper is to reconsiderer and to illustrate Heraclitus' influence on the Stoics, especially Cleanthes. It is a large subject and I make no claim to treat it exhaustively here. But I hope to prove that the present tendency to reduce Heraclitus' influence on early Stoicism is not well grounded. It should be emphasised that I do not intend my thesis to cast doubt upon the Stoics' close attention to positions taken up by other philosophers of their own time. I shall not suggest that Heraclitus was their starting-point in cosmology. But his importance, especially to Cleanthes, so I shall argue, was fundamental. In attempting to demonstrate this, one is faced with a series of questions, all of which seem to be interesting and worth posing for their own sake. What knowledge of Heraclitus did the early Stoics possess? Was their method of interpretation their own or did it derive from the work of others, especially Aristotle and Theophrastus? Did the Stoics merely twist Heraclitus' views to suit their preconceived needs, or has their interpretation, in some cases, a valid basis in Heraclitus' thought? Above all, why did they take an interest in this remote and extraordinarily difficult thinker? ", A. A. LONG, "Heraclitus and Stoicism", Stoic Studies, Berkeley and Los Angeles/London, University of California Press, 1996, pp. 37-38.
} 
terra, a água, o ar, o fogo, transformáveis uns nos outros, segue, de igual modo, a disposição aristotélica. ${ }^{7}$

\section{§ 2.0 vazio infinito.}

A cosmologia dos primeiros Estóicos apresenta, contudo, diferenças específicas que a demarcam do modelo anterior. A concepção de um vazio infinito para lá dos limites do cosmo constitui um dos pontos fundamentais desta doutrina, revestindo simultaneamente o carácter de uma exigência lógica. Vários foram os argumentos utilizados pelos Estóicos com vista a demonstrar a sua existência.

Admitamos que alguém situado na extremidade das estrelas fixas estende a sua mão para lá dessa extremidade. Se o seu movimento não for impedido, será preciso acreditar que um vazio existe no exterior; se o seu movimento for impedido, deve, ainda assim, existir alguma coisa, um corpo, a impedi-lo. Ora, se esse alguém a seguir se colocasse na extremidade deste último corpo, a questão persistiria infinitamente, o que prova que alguma coisa - ou o ser ou o vazio - existe fora do cosmo. ${ }^{8}$

Propriamente estóico é o argumento ligado ao dogma da criação e destruição do mundo. $\mathrm{O}$ mundo não guarda o mesmo volume em todos os momentos da sua história, ele contrai-se na geração e dilata-se na conflagração universal. Tal como os vapores de um líquido, ou o fumo de um sólido em combustão, se propagam em todas as direcções do espaço, do mesmo modo, na conflagração a substância do Universo deve expandir-se para lá da presente periferia do cosmo, exigindo em torno de si um vazio no qual possa propagar-se. «Na verdade, o mundo consumido pelo fogo tornarse-á maior, pois a substância no seu todo dissolver-se-á para tomar a forma do éter, o elemento mais subtil. $\mathrm{O}$ que os Estóicos anteviram, parece-me, ao deixarem na sua teoria um vazio infinito exterior ao mundo, para que, no

\footnotetext{
7 V. Fig. 1. A Terra é vista neste modelo como uma esfera imóvel situada no centro de uma outra muito maior, a esfera das estrelas fixas, que gira para oeste em torno de um eixo fixo. No amplo espaço entre a Terra e a abóbada celeste desloca-se o Sol, a Lua e os cinco planetas então conhecidos: Mercúrio, Vénus, Marte, Júpiter e Saturno. Para lá da última esfera nada existe, nem espaço nem matéria.

8 Trata-se do argumento de Arquitas de Tarento, inicialmente utilizado para provar a infinidade do Universo. Os fragmentos que abordam a questão do vazio encontram-se coligidos em $\mathrm{H}$. von ARNIM, Stoicorum Veterum Fragmenta [de agora em diante designado pela sigla SVF], II, pp. 170-172 [§ 4. Finitum esse mundum et unitum, sed circumdatum inani infinito].
} 
momento em que deva expandir-se infinitamente, não se coloque o problema do espaço susceptível de acolher esta expansão». ${ }^{9}$

Admitir a existência de um vazio exterior não deixa de suscitar algumas questões. Como conciliar, na física estóica, o geocentrismo com a ideia de um vazio infinito fora do mundo, o qual, por definição, carece ele próprio de centro? Como se explica a imobilidade do cosmo no vazio infinito? O que impede a matéria do cosmo de se dispersar e distribuir igualmente por todo o vazio? ${ }^{10}$

\section{§ 3. Força centrípeta e movimento tensional.}

Existe em todo o sistema do mundo um princípio activo, uma tendência ( $\left.\ddot{\epsilon}^{\prime} \xi \backslash S\right)$, responsável pela estabilidade, coerência e união de todas as suas partes. Esta força interna de coesão, explicativa dos movimentos naturais do cosmo, está primariamente presente em todos os corpos como força centrípeta. O tratamento deste problema por parte dos Estóicos ascende à doutrina de Zenão de Cítio:

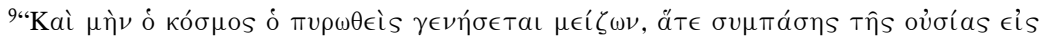

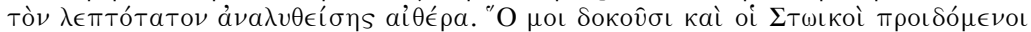

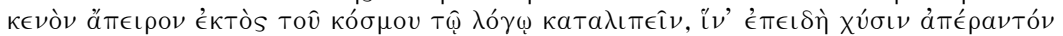

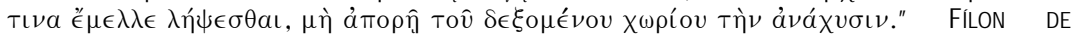
AleXandria, de Aeternitate Mundi, 102. Cf. PlutarCo, de Communibus Notitiis Adversus Stoicos, 35, 1077 b; Cleomedes, de Motu Circulari Corporum Caelestium, I, 1, 2; I, 11, 5. Com Posidónio de Apameia, no segundo período da escola, o estoicismo recusará o vazio infinito, limitando-o às dimensões necessárias à expansão total do mundo na conflagração.

10 Uma síntese destas objecções pode ver-se em PLUTARCo (de Stoicorum Repugnantiis, 44, 1054c) e em inúmeros fragmentos dos comentadores aristotélicos. O tratado do físico estóico CLEOMEDES, de Motu Circulari Corporum Caelestium, constitui uma das mais importantes fontes para o conhecimento da cosmologia dos Estóicos: "Afirmam <os Peripatéticos> que se o vazio existisse fora do mundo a substância ter-se-ia espalhado através dele e dispersado ao infinito. Nós, porém, respondemos que isto não pode acontecer, uma vez que ela possui uma faculdade que a sustém e conserva. $E$ o vazio que a cerca não exerce nenhum efeito. A <substância> conserva-se a si mesma porque é dotada de um extremo poder: contrai-se e expande-se novamente, consoante as suas transformações naturais, ora propagando-se em fogo, ora empreendendo a geração do mundo."

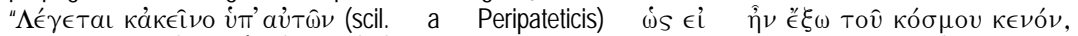

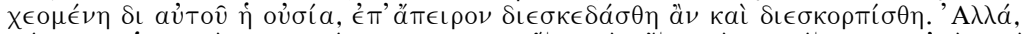

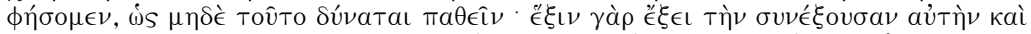

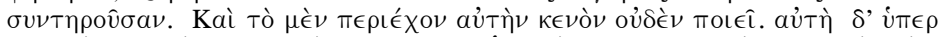

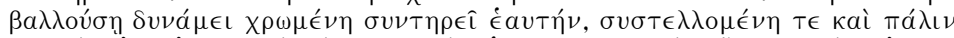

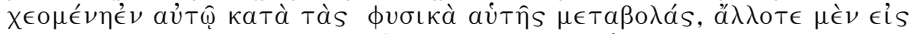

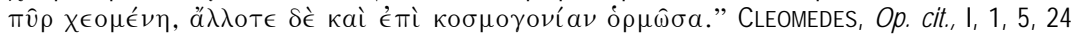
(SVF, II, 540).
} 
Todas as coisas que subsistem no Universo por disposição própria possuem um movimento que as leva para o centro do todo, que coincide com o centro do próprio cosmo. É legítimo, por conseguinte, afirmar que todas as partes do cosmo tendem para o centro do mesmo, em particular aquelas realidades dotadas de peso. Este facto explica não só a imobilidade do cosmo no vazio infinito como também a estabilidade da Terra no centro do cosmo [... ${ }^{11}$

A explicação baseada no movimento centrípeto como factor simultâneo da imobilidade do cosmo foi alvo de crítica. O movimento para o centro pode talvez impedir as partes do cosmo de se desintegrarem e dispersarem em diferentes direcções do vazio, mas dificilmente contribuirá para fazer o cosmo, como um todo, permanecer em repouso e imóvel. A analogia com outros objectos constitui prova disto: uma força interna mantém coesas as partes de uma pedra, por exemplo, mas essa força em nada afecta o movimento da pedra como um todo, a qual tenderá sempre para baixo quando largada no espaço. Os Estóicos procuraram superar esta dificuldade recorrendo ao princípio de tensão, tonos, como equilíbrio de forças. ${ }^{12}$

A teoria do tónos, ou tensão, constitui outro ponto essencial da física estóica e também um dos que mais dúvidas suscita. Alguns fragmentos revelam que a dificuldade relativamente ao conceito fora já sentida pelos

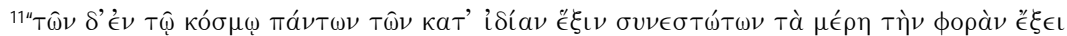

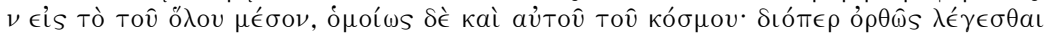

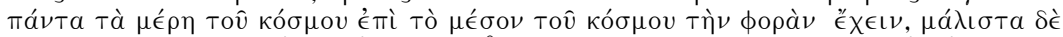

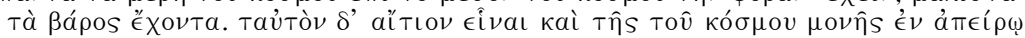

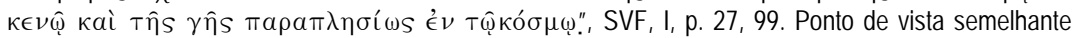
encontra-se em Crísipo (Cf. PLUTARCo, de Stoicorum Repugnantiis, 44, 1055 A). A tendência centrípeta dos corpos no interior da esfera cósmica explica não só a coesão do cosmo, mas também a sua imobilidade no vazio. Cleomedes argumenta explicitamente neste sentido, ao sustentar que a força centrípeta das partes do cosmo anula a objecção de que este se moveria, se existisse um vazio exterior: "O mundo não pode ser arrastado no vazio, visto que tende para o seu próprio centro, que coincide com o seu baixo", CLEOMEDES, Op. Cit., I, 1, 5. O conceito de "vazio infinito" reforça, aliás, este argumento. Sendo o infinito desprovido de qualquer determinação espacial, a deslocação do cosmo no seu seio, numa direcção específica, torna-se impensável. Se, por hipótese, ele se movimentasse no vazio, só poderia ser em direcção ao ponto mais baixo da sua própria massa, que coincide, num mundo esférico, com o seu próprio centro. Ver também CícERo, de Natura Deorum, II, 45, 116; SVF, II, p. 175, 554.

12 Cleantes é o responsável pela introdução, na cosmologia e na física estóicas, do conceito de tónos como "tensão entre contrários".
} 
antigos. Neste sentido se interroga Clemente de Alexandria: «Enigma não é a ligação de todos os seres, nem o movimento circular do mundo de que fala o poeta Arato, mas antes a tensão do pneuma, que tudo penetra e que conserva o cosmo na sua unidade». ${ }^{13} \mathrm{O}$ movimento de tensão corresponde, no contexto da presente análise, a uma contraposição de forças no interior do cosmo, fonte simultânea da sua unidade e permanência.

Três fragmentos permitem conjecturar acerca do modo de operação destas forças naturais. Em primeiro lugar, a argumentação fornecida por Galeno. Imagine-se um corpo físico, uma pedra ou um madeiro, arrastado num sentido por outro corpo. Nesta situação, o primeiro corpo move-se em proporção igual à da força propulsora, que o obriga a avançar tanta distância quanta é capaz de o impelir. Imagine-se que esse corpo é, por sua vez, arrastado em movimento contrário, sempre pela acção de um outro, de modo que a nova força domine o anterior movimento de tracção e o corpo siga, por isso, a direcção do novo movimento. Neste caso, o corpo move-se com menor velocidade e numa distância tanto menor quanto maior for a força que se lhe opõe em sentido contrário. Imagine-se, ainda, o mesmo corpo num terceiro estado, que é o de ser puxado simultaneamente e com idêntica força em direcções opostas. Neste último caso, enquanto o primeiro movimento impele para um lado e o segundo para o outro, contrariando-o, o corpo permanece no mesmo lugar. Mas será que nestas condições ele está em completo repouso? Em semelhantes condições, o corpo move-se ora para cima, ora para baixo, e parece permanecer no mesmo lugar devido ao facto de as deslocações serem muito rápidas e os movimentos se sucederem com intervalos muito curtos. ${ }^{14}$

O raciocínio anterior, acerca da imobilidade de um corpo submetido a tensões contrárias, era ensinado pelos Estóicos e é possível inferir que o mesmo se aplicava ao cosmo como um todo. Dois outros fragmentos, relacionados com Zenão e Crísipo, respectivamente, abordam o mesmo

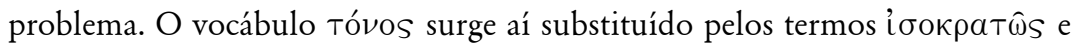

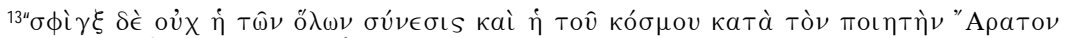

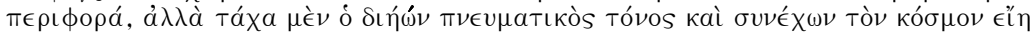
äv.", SVF, II, p. 147, 447.

${ }^{14}$ Cf. SVF, II, p. 148, 450. Nesta explicação de Galeno, o repouso é, na verdade, visto como uma rápida oscilação em torno do ponto de equilíbrio. Esta espécie de movimento estacionário é comentada por SAMBURSkY em Physics of the Stoics, Princeton, Princeton University Press, 19872, pp. 29-33.
} 
¿бoßapés, ambos relacionados com a ideia de «uniformidade» e «equilíbrio de forças». Ambos os excertos recorrem à natureza leve e pesada dos quatro elementos para explicar o equilíbrio destas forças no interior da esfera cósmica e a imobilidade daí resultante:

<Não se pode sustentar em absoluto> que todos os corpos tenham peso, pois o ar e o fogo são sem peso. Embora estes tendam de alguma maneira para o centro da esfera cósmica, permanecem contudo perto da periferia, constituindo a sua parte essencial, já que, pelo facto de serem desprovidos de peso, tendem naturalmente a ir para cima. De modo semelhante, também o cosmo não tem peso, uma vez que é formado na sua totalidade por elementos pesados e por elementos leves. ${ }^{15}$

Segue-se a abordagem de Crísipo, teoricamente idêntica:

Convém dar atenção a Crísipo quando afirma que a estabilidade do Universo provém dos quatro elementos e que a causa do seu repouso reside na igual distribuição dos seus pesos. Visto que dois, a terra e a água, formam o seu substrato pesado e os outros dois, o fogo e o ar, são leves, a causa da disposição do cosmo é a mistura destes elementos. Com efeito, se o cosmo fosse <só> pesado cairia para baixo; do mesmo modo, se fosse <só> leve deslocar-se-ia para cima; contudo, permanece fixo pelo facto de o elemento pesado e o leve se equilibrarem mutuamente. ${ }^{16}$

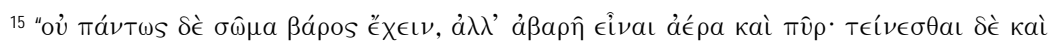

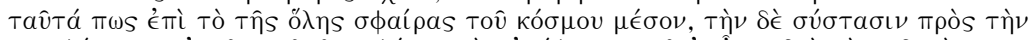

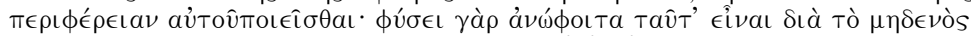

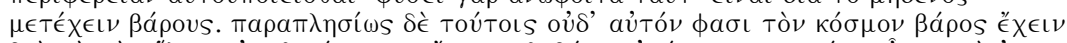

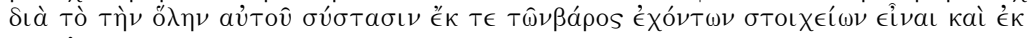

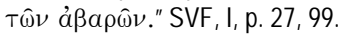

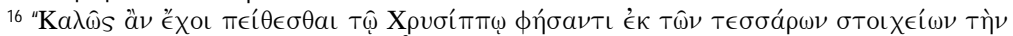

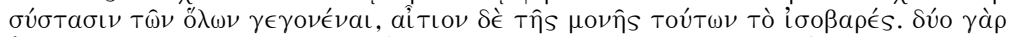

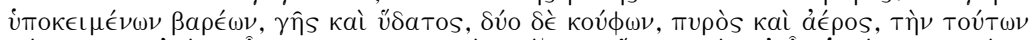

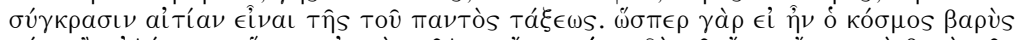

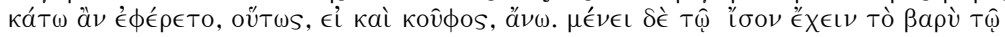
коúфஸ." SVF, II, p. 175, 555. 
O movimento tensional não se define unicamente como contraposição de forças. Assume, mais frequentemente, a forma de um movimento duplo de expansão e contracção, análogo ao movimento da respiração. Fílon de Alexandria chama-lhe sopro de vida eterno. ${ }^{17}$ Para

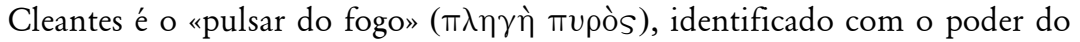
Universo. ${ }^{18}$

Este movimento regular, que representa a alma do mundo, está igualmente presente, sob a forma de eterno retorno, nas teorias sobre a conflagração e a restauração (apokatástasis) universais. No termo do Grande Ano, tendo atingido o ponto mais elevado do seu desenvolvimento, exaurido o todo na combustão final que realiza a purificação do mundo, a substância do Universo contrai-se, recolhendo no seu seio todas as coisas. ${ }^{19}$ Regressada a si, ela realizará infinitamente, segundo a mesma ordem, o processo da origem. Nada haverá no mundo de absolutamente novo em comparação com o que já ocorreu em períodos anteriores, a vida do Universo prosseguirá de forma absolutamente idêntica, até nos mínimos pormenores. Nemésio comenta num conhecido texto a presença deste invariável na história do mundo e dos homens:

Há-de existir novamente Sócrates e Platão e cada um dos homens estará com os mesmos amigos e concidadãos; acreditarão nas mesmas coisas e manusearão os mesmos objectos; cada cidade e aldeia, cada campo, restabelecer-se-á de modo semelhante. A restauração do Universo produzir-se-á não uma vez, mas muitas vezes, ou antes, as mesmas coisas estabelecer-se-ão de modo infinito e eterno. Quanto aos deuses, que não estão sujeitos à corrupção, basta-lhes terem

\footnotetext{
${ }^{17}$ Começa do centro a tender para as superfícies externas e, tocados os limites visíveis, volta para trás, até chegar ao lugar em que havia tomado o primeiro movimento. Este duplo percurso da força de coesão é indestrutível."

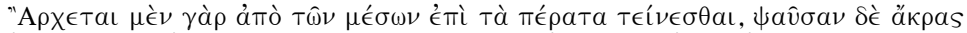

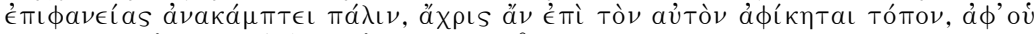

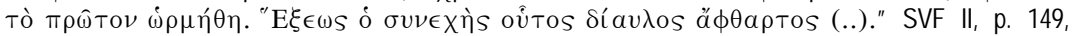
458 [2].

18 V. PLUTARCo, de Stoicorum Repugnantiis, 7, 1034 d (SVF, I, p. 128, 563 [1]).

19 O Grande Ano designa o período de vida do cosmo, o espaço de tempo em que os planetas realizam a sua revolução completa, regressando, por fim, às posições iniciais de onde partiram. Este período foi avaliado pelo estóico Diógenes de Babilónia como correspondendo a 365 vezes 10.800 anos.
} 
seguido de perto um só destes períodos para conhecerem tudo o que deverá suceder nos períodos ulteriores. Com efeito, nada haverá de extraordinário em comparação com o que anteriormente aconteceu, mas tudo será igual, mesmo nos mínimos pormenores. ${ }^{20}$

\section{Considerações finais.}

$\mathrm{Na}$ doutrina da conflagração aqui esboçada e nas alusões dos Estóicos ao Grande Ano é preciso reconhecer os vestígios de um modelo cosmológico amplamente difundido em todo o mundo antigo, cuja origem não é possível precisar. A celebração anual da renovação do Mundo no solstício de Inverno, ligada aos ritos de fecundidade, comum em muitas das antigas culturas, poderá ter conduzido à convicção de que há também nos estratos mais profundos da realidade um grande ano, com as suas estações periódicas, as suas mortes e regenerações. Mediante uma analogia com certos fenómenos naturais que se repetem ciclicamente, ele designaria a duração prevista de um mundo ou de uma era, marcado geralmente, perto do seu final, por acontecimentos cataclísmicos, quase sempre um dilúvio ou uma conflagração.

$\mathrm{Na}$ Índia o espaço de tempo correspondente à vida do mundo é conhecido como um «kalpa», equivalente a 36.000 anos multiplicados por 12.000. O mesmo intervalo de tempo é chamado pelos Árabes «dia do sindhind» e «dia do Universo». Para os Caldeus o mundo encontra-se igualmente sujeito ao dilúvio e à conflagração, fenómenos periódicos que se atribuem a determinadas configurações planetárias.

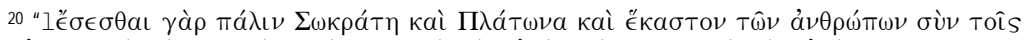

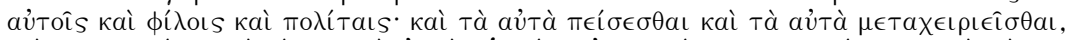

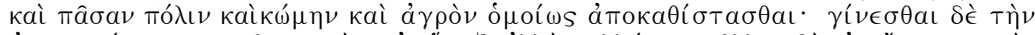

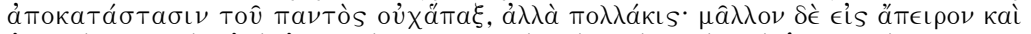

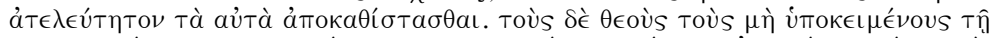

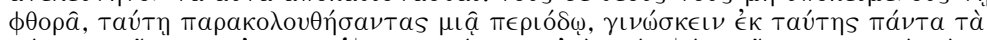

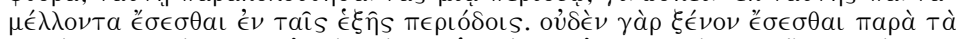

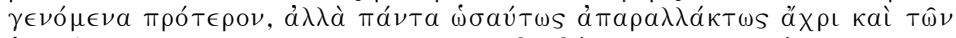

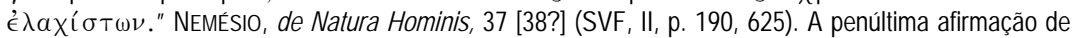
Nemésio é de grande importância na filosofia estóica, pois permite justificar a sua aceitação das práticas oraculares e divinatórias, bem como a sua incorporação na doutrina do destino.
} 
Que a vida do mundo seja periódica, que o seu período tenha por duração o Grande Ano que reconduz todos os planetas ao mesmo ponto do céu, que cada período seja marcado pela alternância de um dilúvio de água e de um dilúvio de fogo, é uma doutrina que, em boa hora, se introduziu na filosofia helénica. Quando Anaximandro, Anaxímenes, Heraclito, Empédocles, os Pitagóricos, Platão, os Estóicos, chamam a atenção para o «ano perfeito», mais não fazem, por conseguinte, do que evocar um dos dogmas essenciais das filosofias e das culturas antigas. ${ }^{21}$

21 Veja-se, a propósito desta temática, P. DUHEM, Le système du monde. Histoire des doctrines cosmologiques de Platon à Copernic. Tome I: La cosmologie hellénique, Paris, A. Hermann et Fils, 1913, pp. $65-85,275-296$. 


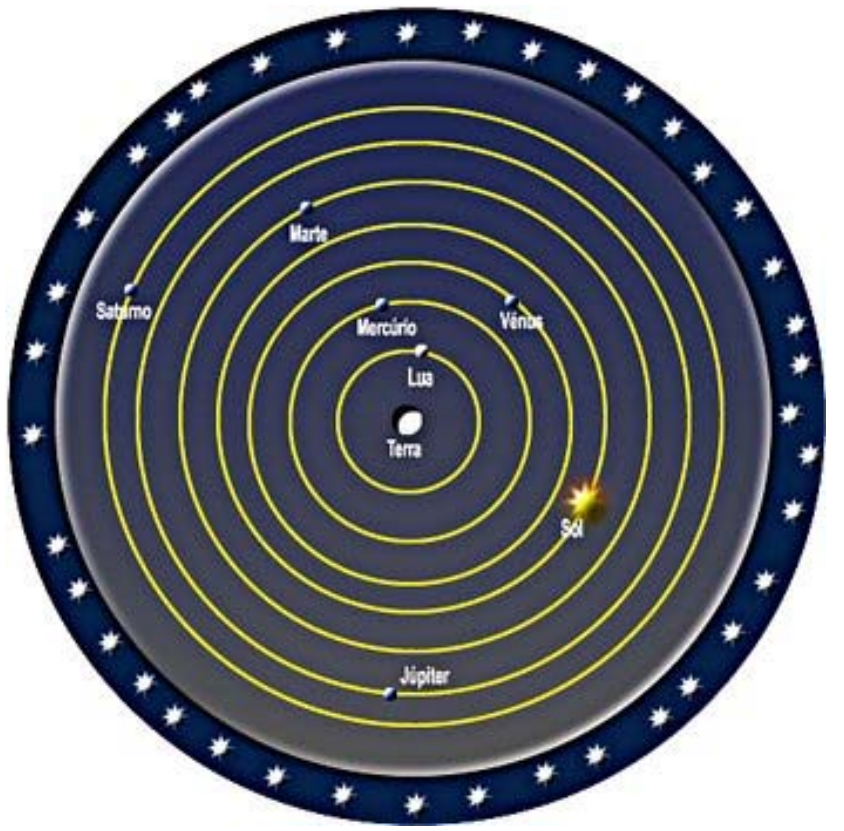

Fig. 1. O geocrentismo. Modelo platónico-aristotélico. 


\section{Referências}

ARnim, H. vON. Stoicorum Veterum Fragmenta, I-IV, Stuttgart: Teubner, 1978-1979.

Cícero. De Natura Deorum (Nature of the Gods), Philosophical Treatises, XIX, translated by H. Rackham. Cambridge: Harvard University Press, 1951.

Cleomedes. Théorie élémentaire (De motu circulari corporum caelestium), texte présenté, traduit et commenté par R. Goulet. Paris : Vrin, 1980.

Diels, H., KranZ, W. Die Fragmente der Vorsokratiker. I-III, Berlin: Weidmannsche Verlagsbuchhandlung, 1956.

Duhem, P. Le système du monde. Histoire des doctrines cosmologiques de Platon à Copernic. Tome I: La cosmologie hellénique. Paris : A. Hermann et Fils, 1913.

Filon De AleXANDria. De Aeternitate Mundi, introduction et notes par R. Arnaldez, traduction par J. Pouilloux . Paris : Cerf, 1969.

Long, A. A. Stoic Studies, Berkeley and Los Angeles/London: University of California Press, 1996.

NeMeSIO De Émeso De Natura Hominis, traduction de Burgundio de Pise, édition critique par G. Verbeke et J.R. Moncho. Leiden: Brill, 1975.

PlatÃo. Les Lois, Euvres Complètes, XI-XII, texte établi et traduit par E. des Places. Paris : Les Belles Lettres, 1951, 1956.

—. Fedro, tradução de M. Pulquério. Lisboa: Ed. 70, 1997.

Plutarco. De Communibus Notitiis Adversus Stoicos (Against the Stoics on Common Conceptions), Moralia, XIII: II, translated by H. Cherniss. Cambridge: Harvard University Press, 1976.

. De Stoicorum Repugnantiis (On Stoic Self-Contradictions), Moralia, XIII: II, translated by H. Cherniss. Cambridge: Harvard University Press, 1976.

Radice, R. Stoici Antichi. Tutti i frammenti raccolti da Hans von Arnim. Milano: Rusconi, 1998.

SAMBuRSKY, S. Physics of the Stoics. Princeton: Princeton University Press, $1987^{2}$.

E-mail: ppgfilosofia@ufpel.edu.br

Recebido: Dezembro/2009

Aprovado: Março/2010 